\title{
INTEGRAÇÃO PROJETO E OBRA EM EMPREENDIMENTO PÚBLICO DE GRANDE PORTE
}

\author{
MOREIRA, Ronan Lana Alves \\ Universidade Federal de Minas Gerais - UFMG, e-mail: ronanlanal@gmail.com \\ ANDERY, Paulo Roberto Pereira \\ Universidade Federal de Minas Gerais - UFMG, e-mail: paulo@demc.ufmg.br
}

\begin{abstract}
RESUMO
O presente trabalho apresenta os resultados iniciais de um projeto de pesquisa de mestrado que está estudando as alterações na coordenação e desenvolvimento de projetos de obras públicas que utilizam a modalidade de Contratação Integrada do RDC - Regime Diferenciado de Contratação. A pesquisa desenvolveu-se no marco metodológico de estudo de caso compreendendo a análise do processo de projeto de duplicação de rodovia federal, com o objetivo de verificar os mecanismos de coordenação e integração entre as fases de projeto e obra, identificando em que medida a Contratação Integrada contribui para a adoção de princípios de Engenharia Simultânea. Os resultados apontam para o fato de que, independentemente de questões legais, a Contratação Integrada possibilitou a elaboração de projetos por frentes de serviço com adequações na fase de obra, permitindo uma maior integração entre os agentes, resultando em melhoria das condições de construtibilidade. Porém, são necessários avanços na formalização do processo de integração e inclusão de ferramentas de tecnologia da informação.
\end{abstract}

Palavras-chave: Gestão do processo de projeto, Regime Diferenciado de Contratação, Contratação Integrada, Integração projeto-obra.

\begin{abstract}
The present work presents the initial results of a research project focused on the changes on the management of public tenders for civil infrastructure projects that make use of the Integrated Contract as part of the Differentiated System of Public Procurement in Brazil. The development of this research is based on a case study, which encompasses the analysis of a project of duplication and enhancements made to a Brazilian Federal Highway. Regardless of legal matters, the results point out that the Integrated Contract allows planning the project in a staggered approach which has many benefits such as: making adjustments to the plan during the construction phase, better staff relationship in the workplace, and improved constructability scenario. Nonetheless, improvement in the integration process and the use of IT tools are necessary steps to be carried out.
\end{abstract}

Keywords: Design management, Differentiated System of Public Procurement, Design-Build, Design-construction interface

\section{INTRODUÇÃO}

A indústria da construção civil enfrenta constantes desafios na condução de projetos devido à fragmentação de contratos, incompatibilidade de alocação de riscos, inexperiência dos contratados e falta de qualificação de corpo técnico (MCKINSEY, 2017).

Uma das causas da falta de integração do setor da construção civil está relacionada ao modelo de contratação padrão da indústria que separa as

MOREIRA, R. L. A.; ANDERY, P. R. P. Integração projeto e obra em empreendimento público de grande porte. In: SIMPÓSIO BRASILEIRO DE QUALIDADE DO PROJETO NO AMBIENTE CONSTRUÍDO, 6., 2019, Uberlândia. Anais... Uberlândia: PPGAU/FAUeD/UFU, 2019. p. 137-147. DOI https://doi.org/10.14393/sbqp19014. 
atividades de projetos e obras.

Particularmente em obras públicas, somente após a conclusão completa de um projeto que se dá a contratação da empresa responsável pala execução da obra, levando em consideração, na maioria das vezes, apenas o menor custo (SULLIVAN et al., 2017).

Na tentativa de melhorar seus processos, a Federal Highway Administration USDOT - autorizou no ano de 1990, o uso experimental de métodos inovadores de entrega de projetos. Dentre os métodos, o mais utilizado até então foi o Design-Build, que contempla a execução conjunta do projeto e da obra por um único ente (MINCHIN et al., 2013).

Em atitude similar, o governo brasileiro instituiu no ano de 2011 o Regime Diferenciado de Contrações - RDC, permitindo em casos específicos a aquisição conjunta de projeto e obra a partir de um anteprojeto de engenharia. A nova modalidade foi denominada de Contratação Integrada, mantendo similaridade com modelo internacional Design-Build (NÓBREGA, 2015).

Apesar do amplo uso do Design-Build desde a década de 1990, persiste ainda a falta de informações de como planejar e implementar procedimentos de gestão para projetos de forma eficaz. Os órgãos governamentais continuam encontrando dificuldades em ajustar as funções de gerenciamento para projetos complexos regidos pelo método (GATTI, 2014).

Nesse contexto, o presente artigo apresenta os resultados iniciais de um estudo de caso exploratório que analisa os mecanismos de coordenação de projetos e integração entre as fases de projeto e obra no âmbito da Contratação Integrada, identificando em que medida esse marco legal contribui para adoção das melhores práticas de gestão do processo de projeto. Não estão sendo considerados aspectos legais ou requisitos associados a outros aspectos da contratação que não sejam técnicos.

\section{FUNDAMENTAÇÃO}

\subsection{A Contratação Integrada e o Design-Build}

De aplicabilidade limitada a alguns tipos de contratações', o RDC foi inspirado nas contratações da União Europeia, dos EUA, nas diretrizes da Organização para a Cooperação e Desenvolvimento Econômico (OCDE) e na experiência brasileira com a modalidade de Pregão (ROJO et al., 2017), tornando uma tendência em substituição da Lei Geral de Licitações (VALENCIA, 2016).

Dentre as inovações do RDC está a modalidade Contratação Integrada, que permitiu a contratação de uma única organização responsável pelos projetos, soluções e execução das obras em casos que envolvam a troca de experiências, tecnologias e incentivo à inovação (BRASIL, 2011).

Estudos internacionais apontam que a integração entre projeto e obra pode reduzir os prazos dos empreendimentos, porém ainda são inconclusivos no que diz respeito a possíveis vantagens no gerenciamento de custos e qualidade (SULLIVAN et al., 2017, PARK e KWAK, 2017 e SHERESTHA et al., 2012), apesar de Minchin et al. (2013) considerar a contratação tradicional um método mais

\footnotetext{
1 Ações integrantes do Programa de Aceleração do Crescimento (PAC), Sistema Único de Saúde - SUS, ampliação, reforma e administração de estabelecimentos penais e de unidades de atendimento socioeducativo, ações no âmbito da segurança pública, melhorias na mobilidade.
} 
confiável.

Especificamente em obras rodoviárias, Tran et al. (2018) identificaram vantagens do Design-Build em termos de custo somente para as obras complementares e em termos de prazo para as obras de recapeamento, restauração e reabilitação. Os autores apontam ainda melhora da produtividade em obras de implantação e reconstrução.

Park e Kwak (2017) salientam que não existe uma regra definida para uso do Design Build, porém sugerem que o método é mais apropriado para grandes projetos, onde os proprietários procuram economia de custos e aceleração de prazos com aumento da flexibilidade.

Em estudos nacionais sobre o assunto, Freire et al. (2016) concluíram que a Contratação Integrada, embora mais próxima dos conceitos de Design Build, ainda não resolve os problemas existentes nas contratações públicas, sendo necessárias exigências adicionais na etapa licitatória, bem como na forma de trabalho dos agentes envolvidos, para a implementação das melhores práticas de gestão de projetos.

Na mesma linha de raciocínio, o Tribunal de Contas da União - TCU constatou que $79 \%$ dos empreendimentos fiscalizados regidos pela Contratação Integrada apresentaram indícios de irregularidades no anteprojeto, acrescentando que os gestores públicos não estão definindo de maneira detalhada o nível de qualidade esperado dos empreendimentos (BRASIL, 2017).

Por fim, Park e Kwak (2017) concluem que o principal objetivo do Design-Build é acelerar o processo de gestão de projeto por meio de Engenharia Simultânea, o que até o momento não vem acontecendo de forma ideal.

\subsection{Engenharia Simultânea e melhores práticas na integração Projeto e Obra}

A Engenharia Simultânea é uma visão sistemática do desenvolvimento integrado e simultâneo dos produtos e seus processos relacionados, incluindo manufatura e assistência. Esse enfoque pretende que os projetistas considerem, de início, todos os elementos do ciclo de vida, do conceito ao descarte, incluindo qualidade, custo, programação e requisitos do cliente (BOUCHLAGHEM et al., 2011).

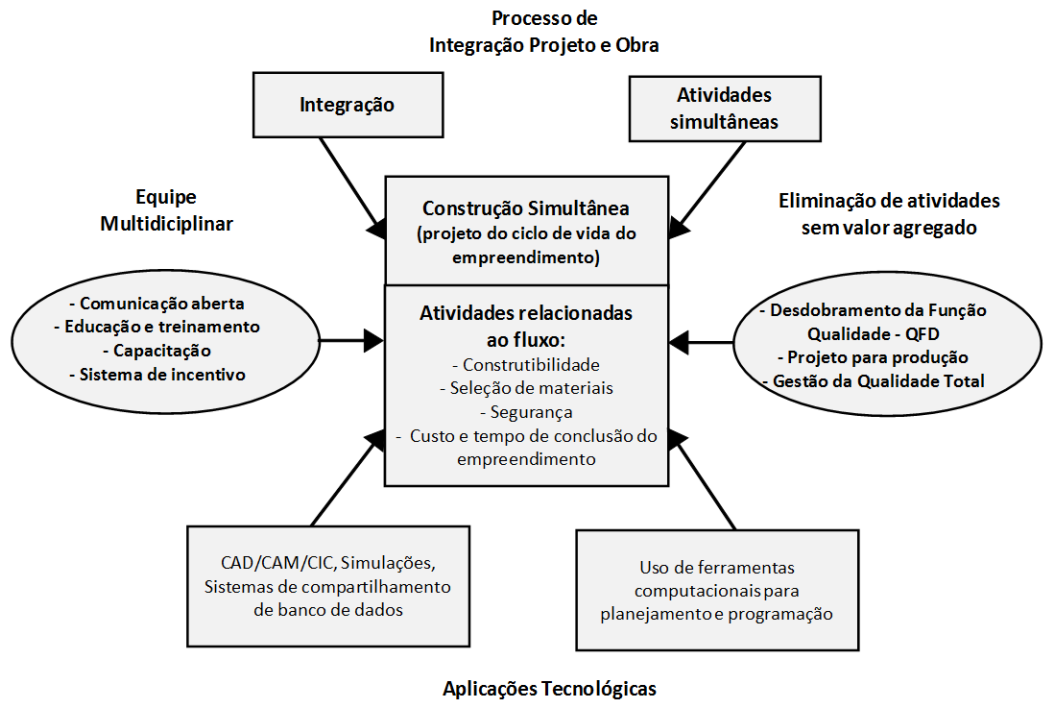

Figura 1 - Aplicação da Construção Simultânea na Indústria da Construção Civil Fonte: Adaptado de Love e Gunasekaran (1997) 
Love e Gunasekaran (1997) propuseram a aplicação da Engenharia Simultânea para a construção, denominada Construção Simultânea, conforme representado graficamente na Figura 1.

Segundo Fabrício (2002), os principais objetivos e vantagens da Engenharia Simultânea na Construção Civil estão relacionados à redução do cronograma, possibilidade de inovações, ampliação da vida útil do empreendimento, construtibilidade e eficiência dos processos a partir das seguintes ações:

- Ênfase no momento da concepção e valorização do projeto;

- Realização em paralelo de várias atividades de desenvolvimento do produto;

- Formação de equipes de projeto multidisciplinares e coordenadas;

- Uso de tecnologia da informação no desenvolvimento do projeto, e

- Orientação para a satisfação dos clientes e usuários, considerando todo o ciclo de vida do empreendimento.

Em estudo específico na área de infraestrutura rodoviária, Gatti (2014) destacou a importância de exigências contratuais para colaboração, incluindo oficina de construção conduzida por um terceiro facilitador, comunicações abertas, interações formais e informais e tomada de decisão justa e transparente.

A Federal Highway Administrativon - USDOT (2006) destaca também a importância da formação de uma equipe contratante treinada e capacitada, incluindo processos formais e específicos para contratos do tipo Design-Build.

No campo de aplicações tecnológicas, Mckinsey (2017) sugere o uso de ferramentas digitais para estabelecer transparência no processo de projeto, facilitar a colaboração, fomentar a inovação e melhorar o acompanhamento de campo a partir do uso do Building Information Modelling - (BIM).

O BIM é um processo em ascensão na indústria da construção que tem por objetivo integrar políticas, processos e tecnologia no gerenciamento de dados de um empreendimento ao longo de todo o seu ciclo de vida, tornando-se uma ferramenta para reduzir a fragmentação da indústria (SUCCAR, 2009).

Pelo exposto nessa breve revisão bibliográfica, a pesquisa inicial se baseou nos principais aspectos da Engenharia Simultânea: integração projeto e obra (atividades simultâneas), eliminação de atividades sem valor agregado (inovação e construtibilidade), equipes multidisciplinares e aplicações tecnológicas.

\section{METODOLOGIA}

O presente trabalho adotou a metodologia Estudo de Caso Exploratório, tendo em vista a complexidade envolvida em uma temática ainda pouco explorada (GIL, 2008). No intuito de se ter uma visão geral do assunto, a pesquisa foi desenvolvida em análise do processo de projetos de parte do empreendimento de duplicação de rodovia federal. O estudo de caso envolveu entrevistas semiestruturadas com coordenadores de projetos $e$ equipe de obras e análise de outras evidências, destacando-se os termos de aceite de análise de projetos e comparativos entre o anteprojeto e o projeto executivo. 


\section{PROCESSO DE PROJETO EM DUPLICAÇÃO RODOVIÁRIA}

A rodovia em estudo é um dos principais corredores rodoviários do estado de Minas Gerais. O trecho da rodovia atualmente em estudos e obras de duplicação e melhoramentos liga a capital Belo Horizonte/MG ao nordeste do estado. O programa foi divido em 11 lotes, sendo os primeiros contratos regidos pela Contratação Integrada iniciados no ano de 2013. Atualmente estão em andamento os contratos referentes à dois lotes, tendo outros dois lotes referentes à construção de túneis concluídos em 2015. Os demais seguimentos estão sem contratos por diversos motivos de ordem técnica, administrativa ou legal (DNIT, 2019).

Devido à complexidade do empreendimento, o escopo do presente trabalho restringiu ao processo de projeto relativo à apenas um dos lotes com contrato em andamento. O lote foi escolhido devido à sua integração com várias obras de arte especiais, além da existência de contratos adjacentes, como exemplificado na Figura 2.

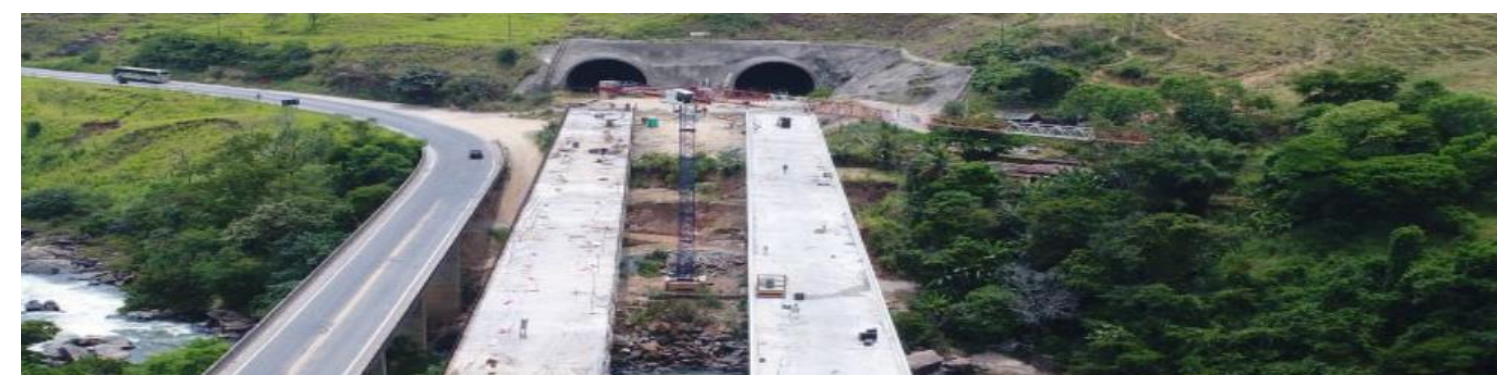

Figura 2 - Ligação entre pontes e túneis no trecho escolhido para a pesquisa

$(11 / 03 / 19)$

Fonte: DNIT (2019)

A execução dos projetos, soluções e obras do lote em estudo está a cargo de um consórcio de empresas sendo oriundo de um contrato rescindido da empresa vencedora do Edital de Licitação original do ano de 2013.

O anteprojeto de engenharia que gerou a contratação foi desenvolvido a partir de um projeto em andamento, encontrando-se em um nível de detalhamento superior ao se comparado com um anteprojeto convencional. O anteprojeto determinava, por exemplo, a utilização de pavimento rígido em detrimento do pavimento flexível e já contemplava detalhes construtivos. Mesmo nessa condição de detalhamento, a Contratação Integrada mantinha a possibilidade de a contratada adotar suas próprias soluções, mantendo ou melhorando as premissas definidas no momento da contratação.

O processo de projeto foi iniciado com a revisão do Estudo de Traçado, definindo assim os dados de entrada para o projeto geométrico. A partir de então, foram criadas três frentes de trabalho distintas: a) pista dupla, b) binário novo e c) binário existente. Em momentos posteriores, as frentes de trabalho foram subdividas em mais partes, que, segundo os entrevistados, eram necessárias para atender as demandas de trechos liberados em campo.

O fluxo de análise de projeto relatado pelos entrevistados (Figura 3) consistia na adaptação do fluxo previsto no Guia de Análise de Projetos Rodoviários da contratante (Figura 4), para atender as condições específicas da Contratação Integrada. 


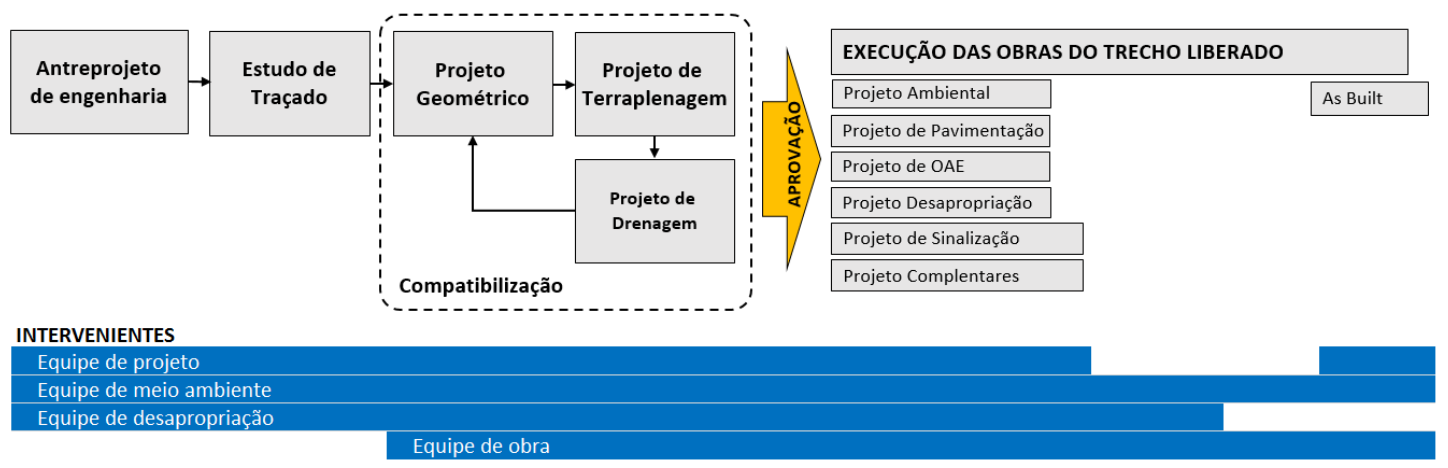

Figura 3 - Fluxo da integração projeto e obra no lote estudado

Fonte: Autor (2019)

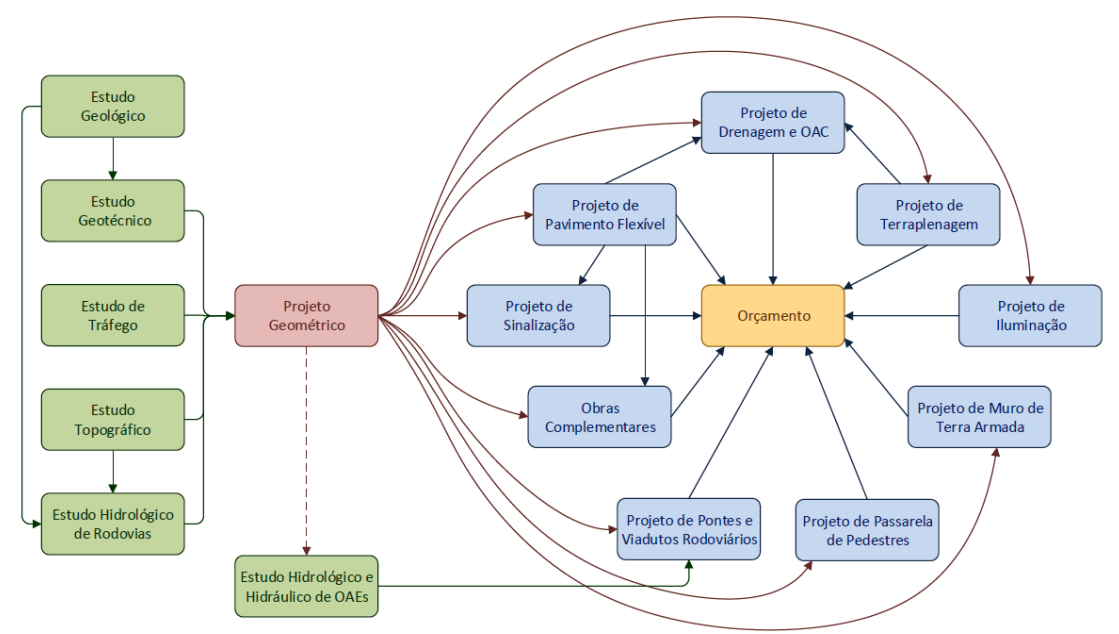

Figura 4 - Fluxo da elaboração de um projeto pelo método tradicional Fonte: DNIT (2018)

Desta maneira, o fluxo do processo de projeto para Contratação Integrada do lote em estudo baseou-se na compatibilização de três disciplinas mandatórias: Geometria, Terraplenagem e Drenagem, considerando ainda a interface com as demais frentes de trabalho e contratos adjacentes, como é o caso verificado das pontes e os túneis apresentados Figura 2.

Segundo o fluxo desenhado em colaboração com os entrevistados, após aprovação das disciplinas mandatórias era autorizado o início das obras do trecho liberado, bem como iniciada a elaboração simultânea dos projetos complementares (ambiental, pavimentação, OAE, desapropriação, sinalização e outros). Os relatórios de Termos de Aceite mostram 65 análises distintas com datas entre abril/2017 até março/2019.

Em questionamento sobre eventos que demonstrariam a integração da equipe de obras com a equipe de projetos, os entrevistados expuseram situações relativas à inovação e/ou construtibilidade conforme descrito a seguir:

- Ponte sobre o ribeirão: a solução proposta pela contratada modificou a superestrutura prevista em vigas pré-moldadas em concreto protendido para vigas metálicas conforme exemplificado na Figura 5. Outra modificação do anteprojeto foi em relação ao novo posicionamento do greide da rodovia, reduzindo o comprimento da Obra de Arte Especial de 315 metros para aproximadamente 225 metros. A obra referente à ponte ainda não foi iniciada e a expectativa dos entrevistados é que tais medidas, apesar de acrescentar trabalhos em terraplenagem, irão reduzir o tempo total de execução de obra, 
tanto em virtude do tamanho da ponte, quanto em função da industrialização de parte do processo produtivo.
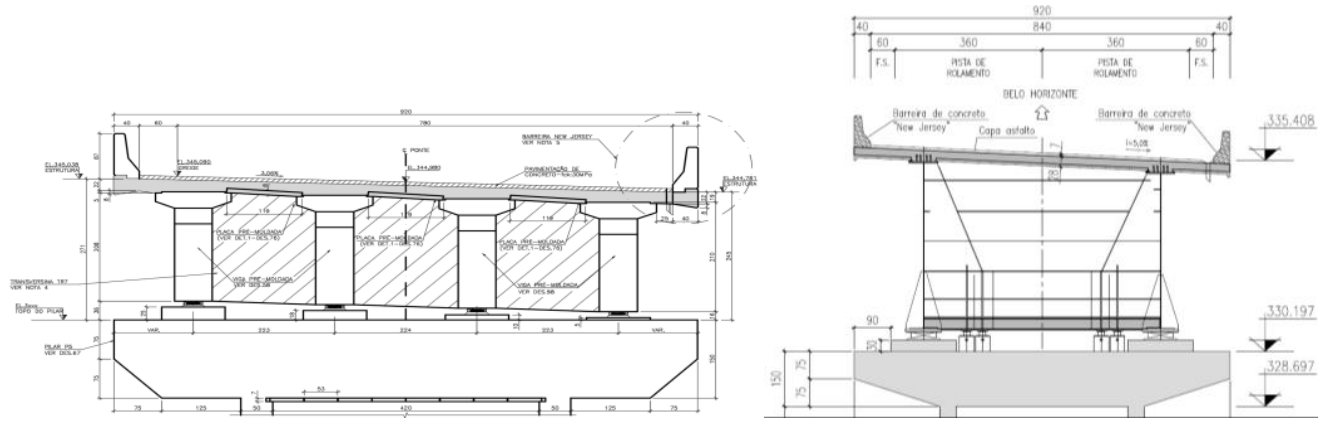

Figura 5 - Exemplo de seção transversal no anteprojeto (a esquerda) e projeto executivo (a direita) para a ponte sobre ribeirão

Fonte: Fornecido pelo órgão público

- Ponte sobre ribeirão e Viaduto sobre a estrada de ferro: tratou-se de duas modificações em sequência do método construtivo de pingadeiras que originalmente seriam moldadas in loco. A primeira modificação aprovada foi a utilização de pingadeira integrada a placas pré-moldadas que serviriam também como forma. Após experiencia na execução dessa nova metodologia na ponte de um ribeirão, a contratante solicitou uma segunda revisão para a construção do viaduto sobre a estrada de ferro. A segunda modificação consistia em utilizar apenas a pingadeira em elementos prémoldados eliminando a forma lateral do tabuleiro. A evolução do método construtivo está detalhada na Figura 6.
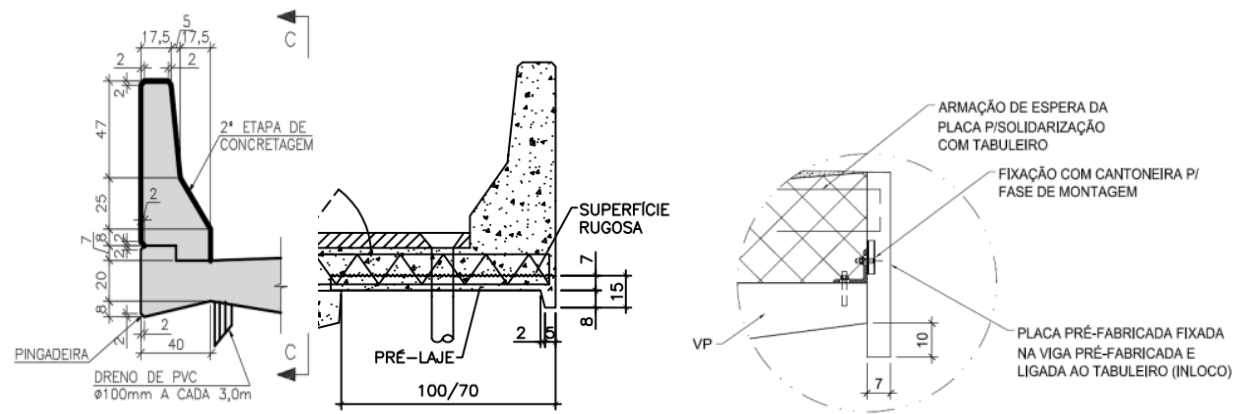

Figura 6 - A partir da esquerda: situação prevista em anteprojeto para pingadeira, primeira solicitação de mudança e detalhe da segunda solicitação de mudança Fonte: Fornecido pelo órgão público

- Alteração de traçado em interferência com linha férrea: a previsão inicial do traçado era o remanejamento de ferrovia aproveitando a topografia existente conforme demonstrado na Figura 7. Entretanto, a contratada, por motivos internos, optou por não remanejar a ferrovia, evitando a interferência e assumindo a necessidade de um maior movimento de terra conforme demonstrado na Figura 8.

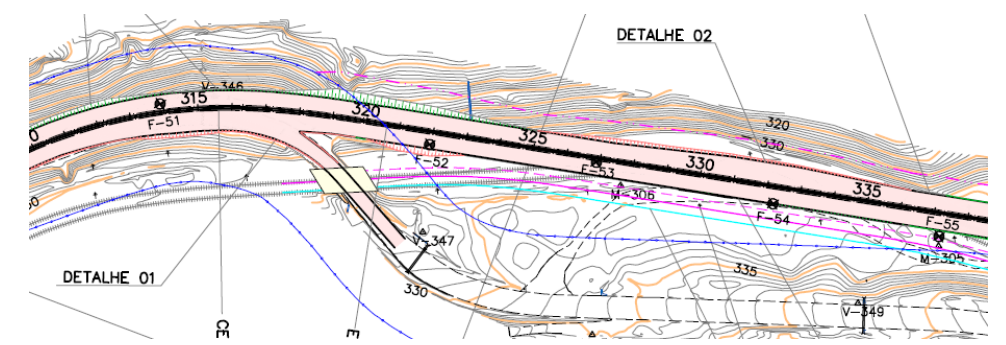

Figura 7 - Solução de anteprojeto para interferência com a rede ferroviária

Fonte: Fornecido pelo órgão público 


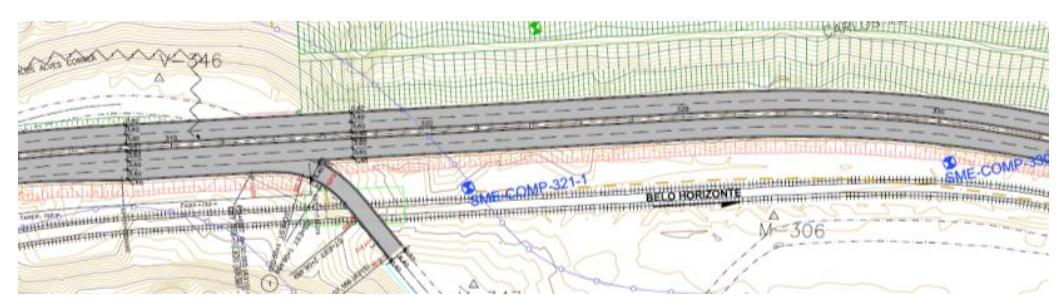

Figura 8 - Situação definida em projeto entre as estacas 315 e 335

Fonte: Fornecido pelo órgão público

Outro favor inovador oriundo das necessidades de obra foi relativo à normatização. Processos internos apontam que a contratante solicitou o uso de equipamento nuclear denominado Gamadensímetro para controle de compactação de aterros em substituição aos métodos do Frasco de Areia e do Speedy. A demanda culminou em uma nova norma governamental, Norma DNIT 405/2017 - ME (DNIT, 2017) expandindo a utilização do método para demais obras.

Por fim, cabe registrar o avanço no uso de equipamentos automatizados, como foi o caso do uso de motoniveladora com lâmina automática. A partir da inclusão do projeto 3D no computador de bordo do equipamento e de uma estação total próxima, a lâmina do equipamento era automatizada, o que eliminou o uso de estacas e possibilitou a oportunidade de melhoria na precisão e acabamento dos serviços.

\section{RESULTADOS PARCIAIS}

De posse das informações obtidas, o presente trabalho irá analisar os seguintes aspectos da Engenharia Simultânea: integração entre projeto e obra (atividades simultâneas), eliminação de atividades sem valor agregado (inovação e construtibilidade), equipes multidisciplinares e aplicações tecnológicas conforme itens a seguir.

\subsection{Integração projeto e obra (atividades simultâneas)}

Como pontos positivos, destacam-se a possibilidade da aprovação dos projetos por trechos que podem ser definidos em função de interferências, questões ambientais, desapropriações e outras de interesse dos envolvidos no empreendimento, podendo gerar aceleração na execução de trechos liberados em detrimento de trechos com soluções mais complexas.

Em termos de oportunidades de melhoria, os Termos de Aceite de Projetos são claros no sentido da existência de atividades simultâneas e paralelas em relação à execução da obra, porém a tramitação dessas análises (65 no total) guarda contempla parte do fluxo relatado na Figura 5. Dessa maneira sugerese a formalização de um fluxo de processo de projeto específico para a Contratação Integrada, registrando suas peculiaridades.

Cabe salientar que questões de prazo não fazem parte do presente trabalho devido à diversidade de fatores externos que se tem notícia, alguns deles relativos ao período de crise notoriamente conhecida no Brasil.

\subsection{Eliminação de atividades sem valor agregado}

Como pontos positivos, destacam-se inicialmente as alterações de projeto que visaram a industrialização de parte do processo e alteração de métodos construtivos que favorecem a manutenção e durabilidade, como são os casos 
relatados da ponte sobre um ribeirão, pingadeiras e alterações de traçado. Cabe destacar também que o anteprojeto de engenharia já exigia a execução do pavimento rígido, de custo inicial mais alto, porém com maior durabilidade e menor necessidade de manutenção.

Em termos de oportunidades de melhoria é interessante potencializar a inovação e construtibilidade a partir de exigências contratuais para colaboração, como por exemplo, formalização de oficinas de ideias conduzida por um terceiro e outras formas de fomentar a interação entre as equipes. A contratante pode também verificar a possibilidade de inclusão nas exigências contratuais para empresas certificadas em sistemas de qualidade reconhecidos no mercado.

\subsection{Equipes multidisciplinares}

Como pontos positivos, os resultados apresentados sobre melhoria de métodos construtivos, alteração de traçado e novo normativo, relatadas pelos entrevistados como advindos da equipe de campo, sugerem as vantagens do uso de equipes multidisciplinares.

Porém, como oportunidades de melhoria, segere-se a definição em contrato da sistemática para a participação da equipe de obras durante o projeto nos mesmos moldes já comentados no item 5.2. Outros fatores importantes para implementação são relativos a ferramentas de comunicação aberta, formal e informal, capacitação dos envolvidos para entendimento das vantagens da integração projeto e obra e criação de sistemas de incentivo à inovação.

\subsection{Tecnologia da informação}

Dentro dos princípios básicos da Engenharia Simultânea, foram verificados poucos avanços em aplicações tecnológicas para subsidiar a integração projeto e obra. Sugere-se de imediato a preparação da equipe contratante para futura exigência do uso do processo BIM - Building Information Modeling em conformidade com ações governamentais já iniciadas, inclusive pelo próprio Departamento Nacional de Infraestrutura de Transportes.

\subsection{Considerações gerais}

Os resultados obtidos guardam relação com a literatura, inclusive internacional, no sentido de que a integração projeto e obra ainda precisa de avanços no processo de gestão de projeto para se beneficiar de todas as vantagens e possibilidades advindas da Engenharia Simultânea.

Cabe destacar que outros avanços já podem ter ocorrido em contratações posteriores tendo em vista que o estudo se baseou em um dos primeiros contratos na modalidade integrada.

Observou-se também que as ações da parte contratante na integração se deram com foco apenas na redução de prazos e melhoria da qualidade, tendo em vista que as questões de custos, via legislação, são tratadas somente na fase de contratação. Com mais estudos, essa questão pode ser motivo de crítica ao modelo em função da modalidade não incentivar a redução de custos por parte do contratante durante a fase de obras.

\section{CONCLUSÃO}

A Contratação Integrada, independente de análise legal, pode ser uma ferramenta importante na evolução das contratações públicas de obras em 
ambientes complexos, tendo em vista a possibilidade da execução de projetos concomitantemente com obras e possibilidade melhoria nas questões de construtibilidade e inovação. Porém, avanços são necessários em treinamento, capacitação e exigências contratuais que determinem o uso de tecnologias de informação e integração entre equipes de obras e projetos no intuito de fomentar e potencializar os benefícios inerentes da Engenharia Simultânea.

\section{REFERÊNCIAS}

BOUCHLAGHEM, D.; SHANG, H.; ANUMBA, C. J.; CEN M.; MILES, J.; TAYLOR, M. ICT - Enabled Collaborative Working Environment for Concurrent Conceptual Design. Architectural Engineering and Design Management, v.1, p. 261-280, 2006.

BRASIL. Lei n.o 12462, de 04 de agosto de 2011. Institui o Regime Diferenciado de Contratações Públicas. Disponível em:

<http://www.planalto.gov.br/ccivil_03/_ato2011-2014/2011/Lei/L12462.htm>. Acesso em: 21 de janeiro de 2019.

BRASIL. Tribunal de Contas da União. Acórdão n 306/2017. Plenário. Relator: Ministro Bruno Dantas. Sessão de 22/2/2017. Disponível em:

<https://portal.tcu.gov.br/inicio/index.htm>. Acesso em: 20 de out. 2018.

DNIT 2017: NORMA DNIT 405/2017 - ME. Disponível em:

<http://ipr.dnit.gov.br/normas-e-manuais/normas/meetodo-de-ensaio-me/dnit405_2017-me.pdf>. Acesso em: 18 mar. 2019.

DNIT 2018. Guia de análise de projetos rodoviários (versão beta V3), n. Jan.

2018. Disponível em: <http://www.dnit.gov.br/planejamento-e-

pesquisa/desenvolvimento-e-projetos-

1/1_GuiadeAnalise_Leituradigital_V3_.pdf>. Acesso em: 18 fev. 2019.

DNIT 2019: Portal BR-381/MG (BH - Valadares) - Anel Rodoviário. Disponível em: <http://portalbr381mg.windata.com.br/>. Acesso em: 03 jun. 2019.

FABRICIO, M. M. Projeto Simultâneo na construção de edifícios. (Tese de Doutorado). Escola Politécnica da Universidade de São Paulo, Escola de Engenharia, São Paulo: 2002.

FREIRE, F.; BOMTEMPO, S.; ANDERY, P. Um estudo exploratório sobre o processo de projeto de obras públicas usando o RDC - Regime Diferenciado de Contratações. Encontro Nacional de Tecnologia do Ambiente Construído, 16., 2016, São Paulo: ENTAC, 2016. p. 2661-2671.

GATTI, U. C.; MIGLIACCIO, G. C.; LAIRD. Design Management in Design-Build Megaprojects: SR 99 Bored Tunnel Case Study. Practice Periodical On Structural Design And Construction., v. 19(1), p. 148-158, 2014.

GIL, A. C. Métodos e técnicas de pesquisa social. 6. ed. São Paulo: Atlas, 2008. $200 \mathrm{p}$.

LOVE, P. E. D.; GUNASEKARAN, A. Concurrent Engineering in the Construction Industry. Concurrent Engineering: Research and Applications, v. 5, n. 2, p. 155162, 1997.

MCKINSEY GLOBAL INSTITUTE. Reinventing construction through a productivity Revolution. Fev. 2017. Disponível em:

<https://www.mckinsey.com/industries/capital-projects-and-infrastructure/our- 
insights/reinventing-construction-through-a-productivity-revolution>. Acesso em: 04 fev. 2019.

MINCHIN JR, R. E.; LI, X.; ISSA, R. R.; VARGAS, G. G. Comparison of Cost and Time Performance of Design-Build and Design-Bid-Build Delivery Systems in Florida. Journal of Construction Engineering and Management, v. 139(10), p. 040130073, 2013.

NÓBREGA, M. O processo de mudança dos mecanismos das compras governamentais no Brasil: vantagens e riscos da contratação integrada. Revista do Tribunal de Contas do Estado de Minas Gerais (TCEMG). Belo Horizonte, v. 33, abr./mai./jun., p. 23-37, 2015.

PARK, J.; KWAK, Y. H. Design-Bid-Build (DBB) vs. Design-Build (DB) in the U.S. public transportation projects: The choice and consequences. International Journal of Project Management, v. 35, n. 3, p. 280-295, 2017.

ROJO, C. A.; LOLI, D. A.; MELLO, G. R. Regime Diferenciado de Contratações e Concorrência Pública: Um estudo sob a ótica da economicidade. RACE -

Revista de Administração, Contabilidade e Economia. Joaçaba, v. 16, n. 1, p. 37-64, jan./abr. 2017.

SHERESTHA, P. P.; O'CONNOR, J. T.; GIBSON JR., G. E. Performance Comparison of Large Design-Build and Design-Bid-Build Highway Projects. Journal of

Construction Engineering and Management, v. 138 (1), P. 1-13, 2017.

SUCCAR, B. Building information modelling framework: A research and delivery foundation for industry stakeholders. Automation in Construction. v. 18, p. 357375,2009

SULLIVAN, J.; ASMAR, E. M.; CHALHOUB, J.; ODEIB H. Two Decades of Performance Comparisons for Design-Build, Construction Manager at Risk, and Design-Bid-Build: quantitative analysis of the state of knowledge on project cost, schedule, and quality. Journal of Construction Engineering and Management, v. 143(6), p. 04017009-1 a 04017009-1 1, 2017.

TRAN, D. Q.; DIRAVIAM, G.; MINCHIN JR, R. E. Performance of Highway DesignBid-Build and Design-Build Projects by Work Types. Journal of Construction Engineering and Management, v. 144(2), p. 040171112-1 a 040171 12-9, 2018.

USDOT - FEDERAL HIGHWAY ADMINISTRATION: Design-Build Effectiveness Study. v. 1307, n. Jan. 2006. Disponível em:

<https://www.fhwa.dot.gov/reports/designbuild/designbuild.pdf>. Acesso em: 20 de out. 2018.

VALENCIA, D. C. Críticas ao regime diferenciado de contratações públicas. Revista Prolegómenos Derechos y Valores. Bogotá, v. 19, n. 38, p. 61-75, jul./dez. 2016. 